\title{
State and prospects of international integration associations development in terms of new challenges
}

\author{
Marina Alekseevna Izmailova ${ }^{1}$, Mikhail Yakovlevich Veselovsky $^{2}$, Alla Vladimirovna \\ Nikonorova $^{3,}{ }^{*}$, Veronika Vitalievna Yagubyants ${ }^{4}$, and Lenar Albertovich Yunusov ${ }^{5}$ \\ ${ }^{1}$ Financial University under the Government of the Russian Federation, Department of Corporate \\ Finance and Corporate Governance, Leningradsky Avenue 49, 125993 Moscow, Russia \\ ${ }^{2}$ Technological University, Department of Management, 141070 Korolev, Russia \\ ${ }^{3}$ Moscow S.U. Witte University, Department of Management, 2nd Kozhukhovsky proezd 12/1, 115432 \\ Moscow, Russia \\ ${ }^{4}$ Moscow State Institute of International Relations (University) of the Ministry of Foreign Affairs of \\ the Russian Federation, School of Business and International Proficiency, Vernadsky Avenue 76, \\ 119454 Moscow, Russia \\ ${ }^{5}$ Moscow State Institute of International Relations (University) of the Ministry of Foreign Affairs of \\ the Russian Federation, Department of Management, Marketing and Foreign Economic Activity, \\ Vernadsky Avenue 76, 119454 Moscow, Russia
}

\begin{abstract}
Research background: The European Union has accumulated significant experience of consolidated economic cooperation over the 28-year history of development. There are the prerequisites for building rational interactions with the Eurasian Economic Union. Significant amount of theoretical and practical data has been accumulated; its analysis allows making conclusions about the intensity of economic cooperation of the European Union with all member states of the Eurasian Economic Union and the prospects for the further development of partnership relations in the future.

Purpose of the article: The aim of the article is to identify the prospects for the development of integration associations on the example of the European Union and the Eurasian Economic Union in modern conditions characterized by the spread of a new coronavirus infection and the preservation of a complicated geopolitical situation.

Methods: The results of the study were obtained using general scientific methods of cognition (induction and deduction, methods of dialectics, analysis and synthesis), analytical research methods (logical and comparative analysis, analysis of economic and statistical indicators), methods of scientific forecasting and expert assessments.

Findings \& Value added: The article submits the current state of integration economic relations analysis results on the example of the European Union and the Eurasian Economic Union as the largest economic and political associations. The analysis of the state and dynamics of the integration associations development, as well as the conditions of their
\end{abstract}

\footnotetext{
${ }^{*}$ Corresponding author: nikonorova-av@mail.ru
} 
functioning, makes it possible to define the current trends in the development of integration associations and their determining factors.

Keywords: integrative unions; integration processes; cross-border interactions; globalization; regionalization.

JEL Classification: F53; F63; O19

\section{Introduction}

The functioning of modern integration associations is influenced by a group of factors, including those that have been operating for quite a long time (a complex geopolitical situation, sanctions restrictions and counter-sanctions measures, trade wars, etc.) and there are a number of new challenges, including a factor of biological genesis - a new coronavirus infection, which has become a powerful impulse of the emerging trend of deglobalization. Under these terms, the conceptual question of the trajectory of the development of integration spaces and their expediency has become particularly acute. In the scientific discussions devoted to the fate of integration associations, criticism and skepticism about their future are clearly heard, at the same time another position is justified - the need to improve, strengthen and increase the effectiveness of integration institutions to counteract the pandemic and preserve the achievements of integration.

The purpose of this work is to identify the prospects for the development of integration associations on the example of the European Union (hereinafter referred to as the EU) and the Eurasian Economic Union (hereinafter referred to as the EAEU) in modern terms characterized by the spread of a new coronavirus infection and the preservation of a complex geopolitical situation. To achieve this goal, it was necessary to solve a number of tasks, including analyzing the state of intra - and inter-integration economic relations between the EU and the EAEU, conducting a comparative analysis of the economic potential of these unions, determining current trends in the development of integration associations and groups of factors that determine them.

\section{Methods}

The conducted research is based on the theoretical basis created by both foreign and Russian scientists. Of particular value were scientific works in which: conceptual approaches to the origins of the effects of trade relations are outlined (Viner, 1950); theoretical foundations of economic integration are revealed (Krugman and Venables, 1996; Lumineau et al., 2021; Tan et al., 2020), the dynamics, stages, and forms of economic integration associations (Balassa, 1967; Glazyev, 2019; Postel-Vinay, 2020); the forecast of the strength of economic integration in the terms of global challenges is given (Chia and Plummer, 2015; Shenkar et al., 2020); the applied aspects of the analysis of integration processes are revealed (Akhunbayev et al., 2020; Froese et al., 2021; Kets and Sandroni, 2021; Köpid, 2015); the vision of possible solutions to integration problems (Jones, 2015; Krugman and Venables, 1996; Oliveira and Lumineau, 2019). The statistical data and analytical reports of the Eurasian Development Bank, international reports of researchers representing the EU and EAEU member states, as well as other materials of other authoritative organizations served as an information base.

The research results were obtained using a group of methods: general scientific methods of cognition (induction and deduction, methods of dialectics, analysis and synthesis), analytical research methods (logical and comparative analysis, analysis of economic and statistical indicators), methods of scientific forecasting and expert assessments. 
Considering the current trends of globalization and regionalization, it is impossible not to take into account the fact that global trade has always been recognized (Balassa, 1967; Viner, 1950) and will remain an important tool for stimulating economic growth and increasing income for many countries (Cramton et al., 2021; Krugman and Venables, 1996). But in the terms of the covid era, it is also quite obvious that the coronavirus crisis will help to intensify the efforts of regional groupings, including the EAEU, in order to increase the stability of supply chains, expand trade relations and deepen cooperation between their participants (Dynkin et al., 2021). Considering the essence of globalization processes (Jones, 2015) more broadly, going beyond the boundaries of economic relations, it can be argued that globalization as a process of uniting world forces to solve urgent problems of humanity, in its essence, will remain, but with regard to economic and political components, it is gradually transforming into a new, regional form, as an effective way to mitigate global shocks. The logical consequence of such a transformation will be the rejection of global trade agreements that have an unnecessarily intrusive nature (Lavrikova and Suvorova, 2020). With this formulation of the issue, the task of preserving a free global market with the support of integration cooperation within the framework of existing associations and emerging transnational interactions becomes particularly relevant.

\section{Results}

An analysis of the existing integration associations in the global space has led to the understanding that the EU continues to be the most economically developed integration association in the world today (König, 2015). The EU demonstrates the advanced practices of consolidated economic cooperation and a high level of national, regional and international cooperation (Ahlstrom et al., 2020; Li and Haleblian, 2021; Postel-Vinay, 2020). At the same time, in the terms of increasing tension in trade relations, the uncertainty in world politics and the strengthening of geopolitical disagreements (Glazyev, 2019; Sartor and Beamish, 2020), there is a slowdown in the growth of the EU economy in 2019: the increase in real GDP was $1.5 \%$, which is lower by $0.6 \%$ compared to 2018 . The consequence of the decline in the economic dynamics of the EU member states was the expansion of the state budget deficit by $0.9 \%$ of GDP and a reduction in industrial production by $1 \%$ (Akhunbayev et al., 2020).

Along with economic problems, in 2019, intra-bloc political problems became particularly acute, the reason for which was the desire for the sovereignty of a number of states. First of all, we should mention the formal withdrawal of the UK from the EU on January 31, 2020 after a 47-year period of membership in it - a very difficult exit, which was crowned with success after the double postponement of the Brexit date in 2019. It is important to emphasize the agreements reached on maintaining partnership relations in the trade, economic and political spheres. In addition, under the terms of Brexit, Northern Ireland retains a partial presence in the EU customs space.

It is impossible not to note the events of October 2019 in Spain - the escalation of the Catalan crisis after a two-year lull: a protest movement broke out again in Barcelona and other cities of Catalonia after the indictment of 12 separatists. The hope for a settlement of the political situation in Spain appears in connection with the resumption of the dialogue between the newly elected Prime Minister of Spain and the central government on the issues of the Catalan crisis.

Against the background of acute economic and political problems, the leadership of the main EU institutions changed in 2019. The European Commission was headed by German representative Ursula von der Leyen, the European Council - former Belgian Prime Minister Charles Michel, the European Parliament-Italian politician David-Maria Sassoli, the 
European Central Bank-Frenchwoman Christine Lagarde. The new leadership will have to solve the accumulated problems in the context of the weakening of the geo-economic and geopolitical positions of the EU, as well as the reduction of its share in world trade and the uncertainty of further trade relations with the UK (which will largely affect the further development of integration processes in the EU) against the background of the global crisis associated with the pandemic of a new coronavirus infection (Dynkin et al., 2021).

It should be noted that an important area of activity of EU leadership should be the realization of the UE's interactions with another major integration entity - the EAEU. Today the EU remains the main foreign trade partner of the EAEU and the strengthening of trade and economic relations between the two leading world integration groups will only serve for the benefit of all their member countries. At the same time, it should be noted with regret that ongoing sanction policy against Russia by the United States and a number of European countries has significantly weakened the interaction between the EU and the EAEU in recent years (Zagashvili, 2020). At the same time, the EAEU countries demonstrate its readiness to cooperate with the EU.

In 2019, a number of constructive discussions took place between representatives of the EU and the EAEU, at which a number of initiatives were discussed, including, for example, the implementation of the "Lisbon - Vladivostok" project, which is supported by more than 60 companies and associations from eight countries, the German-Russian Chamber of Commerce, the German-Eastern Business Association. The agenda of the working meetings included issues of technical regulation, customs procedures, improvement of the tax regulation system, including problems with value added tax (VAT). The issue of the need to normalize relations between the EU and the EAEU became central at the forum "The First Dialogue: Connecting Eurasia - from the Atlantic to the Pacific Ocean", held in Brussels in March 2019.

At the same time, it should be noted that against the background of strained relations between most European countries and Russia, the EU is more actively concluding bilateral cooperation agreements not with the EAEU, but with its individual participants. Thus, the EU signed an expanded partnership and cooperation agreement with the Republic of Kazakhstan in 2015, agreements on integrated and expanded partnership were signed with the Republic of Armenia in 2017 and with the Kyrgyz Republic in 2019. In this regard, it seems necessary to identify the state and results of EU cooperation with each of the EAEU countries separately. The data will be provided as of 31.12.2019.

The analysis of cooperation between the EU and Russia (Akhunbayev et al., 2020) allows us to state the following results achieved:

- Russia is the fifth largest trading partner of the EU in terms of exports (4\%) and the fourth in terms of imports $(7 \%)$;

- The volume of trade is 231,1 billion euros, including: exports- 87,8 billion euros and imports-143,4 billion euros;

- The trade deficit is estimated at 56 billion euros;

- The main objects of trade: raw materials and energy, food and beverages, machinery and vehicles, chemicals and other industrial goods;

- Imported goods from Russia: raw materials and energy (68\%), construction materials (3\%), food and beverages (1\%);

- Exported goods to Russia: machinery and vehicles (43\%), other industrial goods (23\%), chemicals (23\%);

- The largest importers: Germany (28 billion euros), the Netherlands (21,5 billion euros), Italy (14 billion euros), Poland (14 billion euros);

- The largest exporters: Germany (26 billion euros), Italy (8 billion euros), Poland (7,5 billion euros), the Netherlands (7 billion euros). 
The continuing high tension in political relations plays a huge role in the state of trade and economic relations between the EU and Russia: on the one hand, the new EU leadership supports the preservation of existing sanctions against Russia, on the other hand, the Russian side has repeatedly stated that it is impossible to lift retaliatory sanctions measures first. However, against this background, there are emerging positive trends in EU - Russia relations (Arbatova, 2021). So, in June 2019 (after a five-year period of suspension of participation), Russia's membership in the Council of Europe, whose task is to monitor human rights, was restored. To a greater extent, it is worth noting the progress at the level of individual EU countries - examples include: the support of the French president in August 2019 for holding a joint summit with Russia to resolve the Ukrainian crisis; the accession of German companies to the implementation of the Nord Stream-2 construction project; the participation of the German Economy Minister in the main economic forum in Russia for the first time since 2014 .

The EU's relations with the Republic of Belarus - until the recent political events in Belarus - can be assessed as positive (Akhunbayev et al., 2020).

- The US is the second most important Republic of Belarus trading partner - the union accounts for almost $1 / 3$ of the volume of foreign trade of the republic;

- The volume of trade is 10,9 billion euros, including imports $-4,2$ billion euros, exports 6,7 billion euros.

- The main imported goods from Belarus: industrial goods $(30,9 \%)$, mineral fuel $(18,4 \%)$.

- The main exported goods to Belarus: machinery and transport equipment $(42,1 \%)$, chemicals $(19,3 \%)$.

The agreement on simplification of the visa regime for citizens, signed in January 2020 after lengthy negotiations during 2019, is aimed at consolidating the interaction between the EU and the Republic of Belarus. An agreement was reached on the development of a customs cooperation plan for 2020-2023 within the framework of the EU-Belarus customs dialogue for 2016-2019.

The EU has more stable relations with the Republic of Kazakhstan, which became the first Central Asian country which signed an expanded partnership and cooperation agreement with the EU in 2015. Within the framework of this agreement, cooperation is expected in 29 areas - trade, investment, implementation of infrastructure projects, ensuring international and regional security, development of innovations in the field of culture, sports and tourism. The achieved results of cooperation are (Akhunbayev et al., 2020):

- The EU remains one of the largest partners of the republic in the field of trade - the union accounts for up to $40 \%$ of the total trade volume in the country, while Kazakhstan ranks only 22nd in the list of EU trade partners.

- The volume of trade is 24,3 billion euros, including imports of 18,4 billion euros, exports of 5,9 billion euros.

- The main imported goods from Kazakhstan: oil and gas (92,2\%).

- The main exported goods to Kazakhstan: machinery and transport equipment $(52,7 \%)$, chemical product $(18 \%)$.

The analysis of the EU's partnership relations with the Republic of Armenia confirms the partner identified for almost all the EAEU countries, which confirms the high importance of the EU as a trading partner:

- $24,8 \%$ of Armenia's total trade volume is accounted for by the EU, while the country ranks 102 nd in the list of EU trade partners;

- The EU is the largest export market of Armenia (28,4\%) and the second largest import market $(23,1 \%)$; 
- The volume of trade is estimated at 1,2 billion euros, including imports of 407 million euros, exports of 785 million euros;

- Main imported goods from Armenia: industrial goods (50,8\%);

- The main exported goods to Armenia are machinery and transport equipment (35,4\%).

The partnership between Armenia and the EU was launched in 2017 - the Comprehensive and Expanded Partnership Agreement was signed.

The youngest partnership of the EU with the EAEU member states should be called relations with the Kyrgyz Republic, the impetus for the development of which was given by the signing in July 2019 of the agreement on expanded partnership and cooperation between the EU and Kyrgyzstan. Thus, the Kyrgyz Republic became the second country in Central Asia which signed such an agreement with the EU.

The cooperation between the EU and the Kyrgyz Republic is characterized by the following results:

- The least developed trade relations among all the EAEU countries.

- The volume of trade is estimated at 433 million euros, including 104 million euros for imports, 329 million euros for exports.

- The main imported goods from the Kyrgyz Republic: raw materials, except fuel (80,4\%).

- The main exported goods to the Kyrgyz Republic: machinery and transport equipment (44,9\%), chemicals $(25,1 \%)$.

Summarizing the abovementioned the authors note an absolutely fact - the strengthening of trade and economic relations between the EU and the EAEU opens up new prospects and mutual benefits for both unions in terms of trade, tourism, industrial development and geopolitics.

\section{Discussions}

Conducting a comparative analysis of the EU and the EAEU (EconomicData.ru, 2021), presented in Table 1 shows that the EU countries having 2,5 times more population exceed the EAEU in terms of GDP by 10 times thereby producing 2,5 times more gross product per capita.

Table 1. Comparative characteristics of the EU and the EAEU (as of 31.12.2019)

\begin{tabular}{|c|c|c|}
\hline \multirow{2}{*}{ Indicators } & \multicolumn{2}{|c|}{ Integration associations } \\
\cline { 2 - 3 } & EU & EAEU \\
\hline Population, mln.people & 447 & 184 \\
\hline GDP, trillion US \$ & 20,2 & 1,9 \\
\hline Number of member states & 27 & 5 \\
\hline Labor force, men \% & 53,7 & 53,5 \\
\hline Share of employment in agriculture, $\%$ & 4,65 & 18,24 \\
\hline Share of employment in industry, $\%$ & 23,95 & 23,71 \\
\hline Share of employment in the service sector, $\%$ & 71,31 & 59,09 \\
\hline Level of unemployment & 6,27 & 7,56 \\
\hline
\end{tabular}

Source: EconomicData.ru (2021)

At the same time, the GDP of one of the poorest EU countries - Romania, amounting to 12,482 US dollars per capita in 2019, exceeds the same indicator of one of the richest EAEU countries - Russia (11,510 US dollars). These facts give reason to conclude: from the point of view of the economic situation, the EU is significantly ahead of the EAEU. 
Besides, it can be argued that things are more promising in the EU today with regard to the expansion of external economic integration. In terms of the number of potential members, the EU slightly exceeds the EAEU: 5 countries have the status of an official candidate for EU membership (the Republic of Albania, the Republic of North Macedonia, the Republic of Serbia, the Republic of Turkey, the Republic of Montenegro), 2 have the status of potential candidates (the Republic of Bosnia and Herzegovina, the Republic of Kosovo) (Ferrandi et al., 2020). The countries that have expressed a desire to join the EAEU include the Mongolian People's Republic, the Republic of Tajikistan, the Republic of Tunisia, the Republic of Moldova, and the Republic of Uzbekistan.

The EU has a free trade area with more than 30 European and non-European countries. It is fair to note that the EAEU also has a free trade zone, but only with 4 states (the Republic of Vietnam, the Islamic Republic of Iran, the Republic of Singapore, the Republic of Serbia). Negotiations are underway to create similar zones with a number of countries, including the Republic of Cuba, the Arab Republic of Egypt, the Kingdom of Thailand (Zuev et al., 2021). The analysis of export and import volumes (Figure 1) confirms the significant advantage of EU trade relations over the EAEU (Eurasian Economic Commission, 2021).

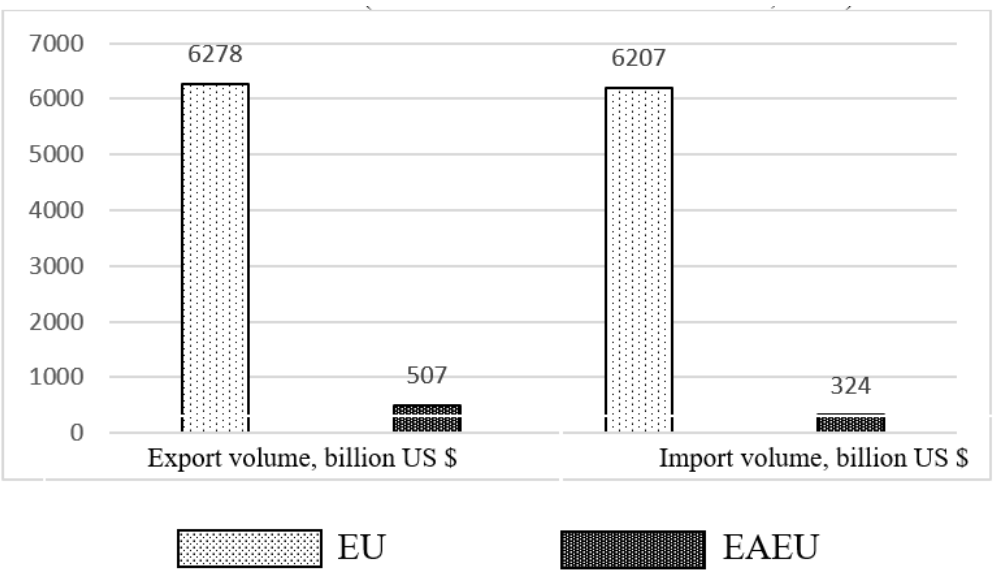

Figure 1. Export and import volume of EU and EAEU

Source: Eurasian Economic Commission (2021)

At the same time, it should be noted that in 2019, the previously outlined positive trends in the foreign trade turnover of the EAEU states remained: with the exception of 2016 (there was a general economic downturn), the volume of mutual trade within the EAEU is steadily growing (Eurasian Economic Commission, 2021) (Figure 2).

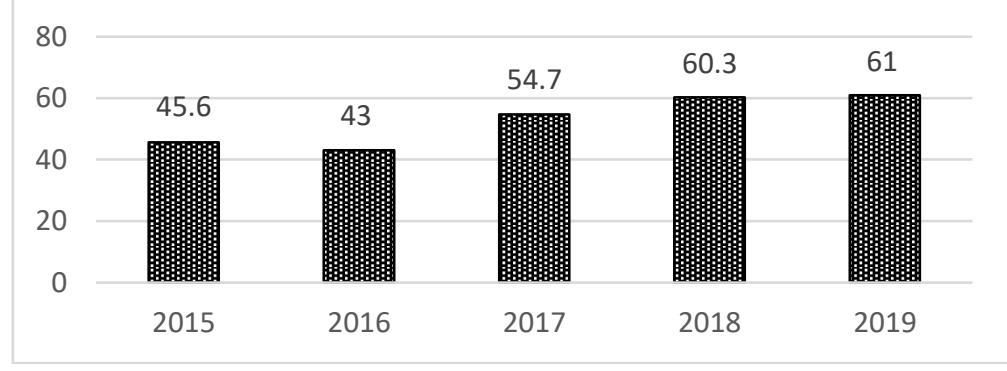

Figure 2. The volume of mutual trade of EAEU, billiard US dollars

Source: Eurasian Economic Commission (2021) 
According to the data of the Eurasian Economic Commission (Eurasian Economic Commission, 2021), in 2019 the value volume of intraregional commodity exchange, calculated as the total volume of exports of the EAEU member states, increased by $1,3 \%$ compared to 2018. At the same time, the growth rate of mutual trade slowed down $(10,1 \%$ a year earlier). In general, over the five years of the EAEU's operation, the volume of mutual trade of the association's members has increased by almost a third. Based on this, it can be stated that the trade integration of the EAEU member states is developing at a steady pace, and this trend has continued throughout 2020.

The existence of a monetary union for most $\mathrm{EU}$ member states contributes to strengthening ties by creating a single financial market, simplifying trade, tourism, eliminating problems with the exchange rate, etc. (Baldwin and Taglioni, 2007). The creation of the EAEU currency zone is at the perspective stage (Chia and Plummer, 2015).

It is fair to note that the EAEU started in the post-crisis period of 2008-2009, which was also marked by the deterioration of the geopolitical situation, when Russia, a member of the EAEU, began to be subjected to sanctions restrictions (Safranchuk et al., 2021). A certain advantage of the EAEU over the EU is the fact that none of the member states of the Eurasian Union has any intentions to leave it in the near future. Regarding the EU, the UK's withdrawal from it and, in general, the growing trend of Euroscepticism is a weak side (Postel-Vinay, 2020).

The assessment of the economic state of integration entities and the prospects for their development today cannot be considered without taking into account the current realities associated with the preservation of the new coronavirus infection, which has most critically affected the global economy.

The rapid coverage of the COVID-19 pandemic in all countries of the world has led to the need to introduce unprecedented restrictive measures in most states, which result in serious losses for the global economy in the short term: a reduction in consumer demand, a slowdown in investment processes, a drop in international trade volumes, a decline in prices for key commodities, tightening financial conditions, primarily for emerging markets.

The impact of the COVID-19 pandemic on the economy of the countries participating in the integration formations occurs in two main directions.

The first direction is associated with the deterioration of foreign economic conditions, weakening demand for export goods, a decrease in income from the sale of raw materials abroad due to falling prices, the destruction of global value chains, a decrease in the volume of money transfers, negative business sentiment, tightening financial conditions, weakening of national currencies. The second direction is determined by a group of factors determined by internal restrictive measures introduced in a number of States to contain the spread of infection. The consequence of these factors is a decrease in the production indicators of a large number of sectors of the economy, among which the service sector is considered the most affected.

Large-scale government measures in the field of fiscal and monetary policy aimed at minimizing the negative economic and social consequences of the COVID-19 pandemic and creating conditions for restoring business activity as the epidemiological situation improves have been and continue to be provided to the economies of the countries participating in the integration formations (Pinskaya et al., 2021). The weakening of the national currencies of the EAEU countries against the background of increased volatility in global commodity and financial markets, most noticeable in the first wave of the pandemic, put pressure on the cost of imported goods and served as a key factor in accelerating inflation in most of the EAEU states in 2020. In the medium term, a significant disinflationary impact is expected from weak domestic demand, which will lead to a significant slowdown in the growth of consumer prices in the EAEU and may lead to a softening of monetary policy. 
Besides, a serious consequence of the influence of COVID-19 on the state and dynamics of integration entities should be considered the possibility of giving impetus to centrifugal forces that can significantly weaken globalization. The result of the global crisis of 20082009 was the end of a long period of liberalization and globalization that began in 1980, and in the last decade there are clear signs of a weakening of the globalization processes. The trend of transferring critical production processes from Asia to their own countries has already become obvious (Dou et al., 2020). In the situation of the current protracted epidemiological and economic crisis, which exacerbates instability in existing international alliances, the governments of many countries express the opinion that it is advisable to reduce interdependence (Chupina, 2021). The main motive for the introduction of protectionist measures is considered to be ensuring the economic and food security of one's own country.

Since the ongoing pandemic has revealed the imperfection and unavailability of the globalized production system to function in the face of new epidemiological challenges, the world community is forced to rethink the supply architecture (Ferrandi et al., 2020), which in the medium term is likely to be built on the dominance of the process of regionalization of production chains.

Regionalization provides for strengthening cross-border cooperation in order to create or restore effective and flexible supply chains in the case of the EAEU, to minimize the threat of excessive dependence on trade with developed industrial countries and emerging market countries (Fedyunina et al., 2020). Regarding the main food and medical products, regionalization will provide safe conditions for the localization of production, as well as increase the immunity of the countries participating in integration associations to new challenges, including such etiology as the COVID-19 pandemic.

\section{Conclusions}

The specifics of the current stage of the development of the global world is the conjugate development of two processes that are mutually exclusive from a theoretical point of view, and from a pragmatic point of view are able to complement each other. We are talking about the processes of globalization based on transparency, liberalization, the rigid effect of the division of labor and country specialization, and about the processes of regionalization, the consequence of which is the creation of integration associations and the strengthening of cross-border interactions. The logical result of regionalization, supplemented by the formation of economic production relations in the form of global value chains and the dominance of cooperation in cooperative relations, is the formation of an enclave in the conditions of international economic relations. Today, the need to promote protectionism, considered as a forced measure to curb the "relentless" liberalization, is becoming increasingly obvious.

The strength of integration ties has been tested for more than a year in the new covid conditions. Regarding the EU, we can say that the union, proclaiming the principle of freedom of movement of people and commodity flows, turned into a territory of closed borders. In contrast to the EU, the leadership of the EAEU demonstrated great solidarity: at the initial stage of the pandemic, the Eurasian Economic Commission adopted a package of measures aimed at combating the epidemic, which allowed avoiding a solidarity crisis. So, in April, the parties agreed to provide a "green corridor" - duty-free import of a number of socially important products, medicines and their components, and at the same time-to stop the export of medicines and personal protective equipment. In addition, decisions were made to protect the rights of migrant workers, for example, Russia extended the validity of work patents for citizens of the EAEU countries. 


\section{References}

1. Akhunbayev, A.M., Dauranov, T.Sh., Kuznetsov, A.S., \& Petrosyan, A.R. (2020). Eurasian economic integration-2020. Moscow: EDB Publications.

2. Ahlstrom, D., Arregle, J. L., Hitt, M. A., Qian, G., Ma, X., \& Faems, D. (2020). Managing technological, sociopolitical, and institutional change in the new normal. Journal of Management Studies, 57(3), 411-437.

3. Arbatova, N. (2021). Russia and the European Union: deferred partnership. World Economy and International Relations, 65(5), 14-27.

4. Balassa, B. (1967). Trade creation and trade diversion in the European common market. The Economic Journal, 77, 1-21.

5. Baldwin, R., \& Taglioni, D. (2007). Trade effects of the Euro: a comparison of estimators. Journal of Economic Integration, 22(4), 780-818.

6. Chia, S. Y., \& Plummer, M. G. (2015). ASEAN economic cooperation and integration: progress, challenges and future directions. Cambridge University Press.

7. Chupina, D. (2021). Coronacrisis in the EU: a knockout or a springboard for integration? World Economy and International Relations, 64(4), 42-49.

8. Cramton, C. D., Köhler, T., \& Levitt, R. E. (2021). Using scripts to address cultural and institutional challenges of global project coordination. Journal of International Business Studies, 52(1), 56-77.

9. Dou, H., Clerc, P., \& Juillet, A. (2020). Changing priorities for strategic planning from national to territorial levels. Foresight and STI Governance, 14(3), 88-99.

10. Dynkin, A., Telegina, E., \& Halova, G. (2021). Prospects and challenges of international economic and energy cooperation after the COVID-19 pandemic. World Economy and International Relations, 65(3), 5-10.

11. Economy of the member countries: The Eurasian Economic Union. (2021, October 1). EconomicData.ru. https://www.economicdata.ru/union.php?menu=economicunions\&un_id=27\&un_ticker=EAEU\&union_show=economics

12. Eurasian Economic Commission: official website. (2021, October 1). http://eec.eaeunion.org/

13. Fedyunina, A. A., Simachev, Yu. V., Kuzyk, M. G., \& Averyanova, Yu. V. (2020). Sectoral features of the integration of the Russian economy into global value chains and consequences for structural policy. Journal of the New Economic Association, 3(47), $106-127$.

14. Ferrandi, R., Banhedi, M., Sziladi, G., \& Hladoni, O. (2020). Responding to the crisis caused by the COVID-19 pandemic with the help of competition policy. Appendix to the issue on competition policy in Eastern Europe and Central Asia. Budapest: The OECDGWH Regional Competition Center in Budapest (Hungary).

15. Froese, F. J., Klar S., Stoermer, S., \& Reiche, B. S. (2021). Best of both worlds: How embeddedness fit in the host unit and the headquarters improve repatriate knowledge transfer. Journal of International Business Studies, 52, 1331-1349.

16. Glazyev, S. Yu. (2019). The EAEU-EU: prospects for a comprehensive economic agreement. Eurasian Integration: Economics, Law, Politics, 4, 11-14.

17. Jones, K. (2015). Reconstructing the World Trade Organization for the 21 st century. An Institutionsl Approach. Oxford University Press.

18. Kets, W., \& Sandroni, A. (2021). A theory of strategic uncertainty and cultural diversity. Review of Economic Studies, 88(1), 287-333. 
19. König, J. (2015). European integration and the effects of country size on growth. Journal of Economic Integration, 30(3), 501-531.

20. Krugman, P., \& Venables, A. J. (1996). Integration, specialization, and adjustment. European Economic Review, 40, 959-967.

21. Lavrikova, Yu. G., \& Suvorova, A.V. (2020). Optimal spatial organization of the regional economy: search for parameters and dependencies. The Economy of the Region, 16(4), 1017-1030.

22. Li, C., \& Haleblian, J. (2021). The influence of nation-level institutions on acquisition premiums: a cross-country comparative study. Journal of Management.

23. Lumineau, F., Hanisch, M., \& Wurtz, O. (2021). International management as management of diversity: reconceptualizing distance as diversity. Journal of Management Studies, 58(6), 1644-1668.

24. Oliveira, N., \& Lumineau, F. (2019). The dark side of interorganizational relationships: an integrative review and research agenda. Journal of management, 45(1), 231-261.

25. Pinskaya, M. R., Steshenko, Yu. A., \& Tsagan-Mandzhieva, K. N. (2021). Tax support during the coronacrisis: who should I help? Economic Issues. 5, 129-144.

26. Postel-Vinay, K. (2020). Globalization 4.0 and new models of international cooperation. Bulletin of International Organizations: Education, Science, New Economy, 15(2), 8292.

27. Safranchuk, I. A., Zhornist, V. M. \& Nesmashny, A. D. (2021). Hegemony and the world order: an overview of the concept of "complex hegemony". Bulletin of International Organizations, 16(1), 172-183.

28. Sartor, M. A., \& Beamish, P. W. (2020). Integration-oriented strategies, host market corruption and the likelihood of foreign subsidiary exit from emerging markets. Journal of International Business Studies, 51(3), 414-431.

29. Shenkar, O., Tallman, S.B., Wang, H., \& Wu, J. (2020). National culture and international business: a path forward. Journal of International Business Studies.

30. Tan, D., Su, W., Mahoney, J. T., \& Kor, Y. (2020). A review of research on the growth of multinational enterprises: a Penrosean lens. Journal of International Business Studies, 51(4), 498-537.

31. Viner, J. (1950). The customs union issue. Carnegie Endowment for International Peace, New York.

32. Zagashvili, V. (2020). The European Union: trade agreements of the second generation. World Economy and International Relations, 64(7), 26-33.

33. Zuev, V. N., Ostrovskaya, E. Ya., Scriabina, V. Yu., \& Kalachigin, G. M. (2021). Features of the EAEU strategy for the formation of a FTA network. Economic Journal of the Higher School of Economics, 25(1), 42-64. 